\title{
A Comparative Study of Laparoscopically Assisted Vaginal Hysterectomy and Non-descended Vaginal Hysterectomy
}

\author{
${ }^{1}$ De Reena, ${ }^{2}$ Sebanti Goswami
}

\begin{abstract}
Introduction: The present study was done to compare nondescended vaginal hysterectomy (NDVH) and laparoscopically assisted vaginal hysterectomy (LAVH) with reference to indications, operative complications and outcome.
\end{abstract}

Materials and methods: This prospective longitudinal comparative study was conducted in the Department of Obstetrics and Gynecology, Medical College and Hospital, Kolkata, from November 2010 to October 2011. Judging the inclusion and exclusion criteria a sample size of 36 patients for NDVH and 31 patients for $\mathrm{LAVH}$ were selected randomly. The outcome of each surgical procedure was analyzed by standard statistical methods. Appropriate test of significance was applied (t-test) with $p<0.05$ as level of significance.

Results: The mean duration of NDVH was 65 minutes and that of LAVH was 93.87 minutes. The difference was highly significant as $p$ value was 0.000 . The mean pain score analyzed by visual analog scale (VAS) in NDVH was 2.334 and 2.581. This was not statistically significant $(p=0.636)$. There was no significant difference in hospital stay in either group.

Conclusion: Laparoscopically assisted vaginal hysterectomy has the advantage of visualization of the pelvic structure from above and occasional dissection and adhesiolysis. But NDVH supersedes in its approach through the naturally created route, being faster, less expensive and results in a similar hospital stay and convalescence.

Keywords: Hysterectomy, Laparoscopically assisted vaginal hysterectomy, Non-descended vaginal hysterectomy, Visual analog scale.

How to cite this article: Reena D, Goswami S. A Comparative Study of Laparoscopically Assisted Vaginal Hysterectomy and Non-descended Vaginal Hysterectomy. J South Asian Feder Obst Gynae 2014;6(2):101-103.

Source of support: Nil

Conflict of interest: None declared

\footnotetext{
${ }^{1}$ Medical Officer, ${ }^{2}$ Associate Professor

1,2Department of Obstetrics and Gynecology, Medical College and Hospital, Kolkata, West Bengal, India

Corresponding Author: Sebanti Goswami, Associate Professor, Department of Obstetrics and Gynecology, 317 New Raipur (Dabur Park), Flat No. 1B, Kolkata-700084, West Bengal, India, Phone: 9831135933, e-mail: sebantigoswami@ yahoo.co.in
}

\section{INTRODUCTION}

Hysterectomy is the most common operation performed by the gynecologist, second only to cesarean delivery. The steps have been modified down the ages to make the surgery an effective yet a safe one. The arena of indications has widened its parameters. The uterus can be removed using any of a variety of techniques or routes including abdominal, vaginal or laparoscopic. The present study was done to compare nondescended vaginal hysterectomy (NDVH) and laparoscopically assisted vaginal hysterectomy (LAVH) with reference to indications, operative complications and outcome.

\section{MATERIALS AND METHODS}

This prospective longitudinal comparative study was conducted in the Department of Obstetrics and Gynecology Medical College and Hospital, Kolkata, from November 2010 to October 2011 after obtaining the clearance from the institutional Ethics Committee. Judging the inclusion and exclusion criteria and the prevalence of such cases in 1 year, a sample size of 36 patients for NDVH and 31 patients for LAVH were selected randomly.

\section{Inclusion Criteria}

Age $>30$ years, uterine size $<12$ weeks, benign pathology.

\section{Exclusion Criteria}

Uterine size more than 12 weeks, more than one cesarean section in the past, sub pubic angle less than $90^{\circ}$, bituberous diameter less than $9 \mathrm{~cm}$, any malignancy, adnexal mass, pelvic organ prolapse, endometriosis, pelvic infection, patient having medical complications: diabetes, heart disease, bleeding diathesis. Patients were recruited from the gynecology OPD. Detailed history taking and clinical examination was done. They were then subjected to routine investigations and some specific investigations after which they underwent LAVH or NDVH according to randomization. They were then monitored and all relevant data were collected for analysis. Parameters studied were: indication of hysterectomy, type of hysterectomy (LAVH/ $\mathrm{NDVH}$ ), operative time, Estimated blood loss, weight of uterus, postoperative pain (visual analog scale (VAS) and requirement of analgesia), intraoperative complications, 
postoperative complications. The outcome of each surgical procedure was analyzed by standard statistical methods, e.g. tabulation, proportion (\%), mean/standard deviation. Appropriate test of significance was applied (t-test) with $\mathrm{p}<0.05$ as level of significance.

\section{RESULTS}

Majority of women in NDVH as well as in LAVH group belonged to the 45 to 50 years age group. Most of the patients of either group belonged to parity $\mathrm{P} 3$.

As is evident from Table 1, the mean blood loss in the $\mathrm{NDVH}$ group was $112.92 \mathrm{ml}$ and that in the LAVH group was $97.58 \mathrm{ml}$. The p-value was 0.060 which was not significant.

The Table 2 reflects that the mean duration of NDVH was 65.00 minutes and that of LAVH was 93.87 minutes. The difference was highly significant as p-value was 0.000 .

The Table 3 shows that the mean weight of the uterus in NDVH was $186 \mathrm{gm}$ and LAVH was within $176 \mathrm{gm}$. The difference was not statistically significant. This is probably because we restricted the size of the uterus to less than 12 weeks in both the groups.

The Table 4 shows that there is no significant difference in hospital stay for NDVH and LAVH.

The mean pain score analyzed by VAS in NDVH was 2.334 and 2.581. This was not statistically significant ( $\mathrm{p}=$ 0.636 ) as shown in the Table 5.

\section{DISCUSSION}

Although hysterectomy was initiated in the yester years through the vaginal route, with the passage of time abdominal route became the more travelled one. With the advent of better anesthesia and expansion of the horizon of laparoscopic techniques, there has been a gradual shift from the conventional abdominal route to laparoscopically assisted vaginal hysterectomy.

The commonest indication of LAVH and NDVH in our study was dysfunctional uterine bleeding where as that in the study by Nur Nahar Khanam ${ }^{1}$ et al was fibroid. The mean value of duration of operation for NDVH was 65 minutes and LAVH was 93.87 minutes. The p-value was 0.000 which was highly significant. Similarly in a study by Bobin $\mathrm{L}^{2}$ et al most of the patients required more than 90 minutes for LAVH. In the study of Nur Nahar Khanam ${ }^{1} \mathrm{NDVH}$ group required $<90$ minutes and LAVH group needed $>2$ hours. The mean duration of LAVH was longer even in studies conducted by Johnson $\mathrm{N}^{3}$ et al and Drahonovsky $\mathrm{J}^{4}$ et al. Drahonovsky J et al summed up in their study that, in women with nonmalignant disease of the uterus, vaginal hysterectomy had the shortest operating time (66 min) and LAVH had an acceptable operating time ( $85 \mathrm{~min})$. In a study by Song $\mathrm{T}^{5}$ et al a total of $2012 \mathrm{LAVH}$ procedures were performed. The mean duration of the operation was $102 \pm 32$ minutes which was comparable to our study. Roy $\mathrm{KK}^{6}$ et al showed in their study that NDVH took least operative time compared to LAVH. Thus, the LAVH group had higher mean operation time compared to that of NDVH.

The mean operative blood loss for NDVH was $112.92 \mathrm{ml}$ and for LAVH was $97.58 \mathrm{ml}$. The p-value was 0.060 which was not significant. Nur Nahar Khanam ${ }^{1}$ et al found that the need for blood transfusion was comparatively high in LAVH group (57.1\%) than that in NDVH group (31.3\%). In a study by Drahonovsky J ${ }^{7}$ et al LAVH had higher blood loss compared to vaginal hysterectomy. However, Horng $\mathrm{SG}^{8}$ concluded that estimated blood loss were significantly reduced in LAVH $(<0.001)$. Roy $\mathrm{KK}^{6}$ et al showed in their study that in NDVH blood loss $(\mathrm{p}=0.02)$ was significantly lesser compared to LAVH.

The mean uterine weight for NDVH was 186.25 gms and that in LAVH was $176.29 \mathrm{gm}$. The p-value was 0.301

Table 1: Distribution of patients according to type of operation and amount of blood loss

\begin{tabular}{lll}
\hline Type & $\begin{array}{l}\text { Peroperative bleeding } \\
(m l)(\text { mean } \pm \text { SD })\end{array}$ & $\begin{array}{l}\text { Significance }(t, p) \\
\text { value }\end{array}$ \\
\hline NDVH $(n=36)$ & $112.92 \pm 30.9$ & $\mathrm{t}_{\mathrm{df65}}-1.91$ \\
LAVH $(\mathrm{n}=31)$ & $97.58 \pm 34.67$ & $\mathrm{p}=0.060$ \\
\hline
\end{tabular}

Table 2: Distribution of patients according to the type of operation and duration of operation

\begin{tabular}{lll}
\hline Type & $\begin{array}{l}\text { Duration of operation } \\
(\text { min })(\text { mean } \pm S D)\end{array}$ & $\begin{array}{l}\text { Significance }(t, p) \\
\text { value }\end{array}$ \\
\hline NDVH $(n=36)$ & $65.00 \pm 14.04$ & $\mathrm{t}_{\mathrm{df65}}-6.66$ \\
LAVH $(\mathrm{n}=31)$ & $93.87 \pm 21.16$ & $\mathrm{p}=0.000\left(6.78 \times 10^{-9}\right)$ \\
\hline
\end{tabular}

Table 3: Distribution of patients according to the type of operation and weight of uterus

\begin{tabular}{lll}
\hline Type & $\begin{array}{l}\text { Uterine weight }(\mathrm{gm}) \\
(\text { mean } \pm \text { SD) }\end{array}$ & $\begin{array}{l}\text { Significance }(t, p) \\
\text { value }\end{array}$ \\
\hline NDVH $(\mathrm{n}=36)$ & $186.25 \pm 36.29$ & $\mathrm{t}_{\mathrm{df65}}-1.04$ \\
LAVH $(\mathrm{n}=31)$ & $176.29 \pm 41.25$ & $\mathrm{p}=0.301$ \\
\hline
\end{tabular}

Table 4: Distribution of patients according to duration of hospital stay

\begin{tabular}{lllll}
\hline $\begin{array}{l}\text { Hospital stay } \\
\text { (days) }\end{array}$ & NDVH & Percentage & LAVH & Percentage \\
\hline$<3$ & 6 & 17 & 18 & 58 \\
$>3$ & 30 & 83 & 13 & 42 \\
\hline
\end{tabular}

Table 5: According to the type of operation and postoperative pain analyzed by VAS

\begin{tabular}{lll}
\hline Type & $\begin{array}{l}\text { Postoperative } \\
\text { pain }(V A S \text { score }) \\
(\text { mean } \pm S D)\end{array}$ & $\begin{array}{l}\text { Significance }(t, p) \\
\text { value }\end{array}$ \\
\hline NDVH $(\mathrm{n}=36)$ & $2.334 \pm 2.16$ & $\mathrm{t}_{\mathrm{df65}}-0.47$ \\
LAVH $(\mathrm{n}=31)$ & $2.581 \pm 2.08$ & $\mathrm{p}=0.636$ \\
\hline
\end{tabular}


which was not significant. This similarity is a reflection of the inclusion criteria where uterine size below 12 weeks was enrolled in the study. Chang $\mathrm{WC}^{9}$ et al concluded that when a cut off value of 350 gm of uterine weight was used NDVH took a longer operation time. There was a linear correlation between uterine weight and operating time. In a study by Song $\mathrm{T}^{9}$ et al a total of 2012 LAVH procedures were performed, where the mean uterine weight were $305 \pm$ $168 \mathrm{gm}$. In 196 (9.7\%) cases, the uterine weight was more than $500 \mathrm{gm}$.

Duration of hospital stay for both the groups was almost same. However, Candiani $\mathrm{M}$ et $\mathrm{al}^{10}$ concluded that laparoscopic hysterectomy results in a shorter hospital stay. Horng $\mathrm{SG}^{11}$ et al concluded in their study that there were no statistically significant difference in postoperative hospital stay between LAVH and vaginal hysterectomy which is a mirror reflection of our study.

In our study, postoperative pain was noted after 4 hours and the rating was done according to the VAS. There was no significant statistical difference $(p=0.636)$ between the two groups. In a study by Bronitsky $\mathrm{C}^{5}$ et al, LAVH caused less patient discomfort in comparison to vaginal hysterectomy. However, in a study by Roy $\mathrm{KK}^{6}$ et al no significant difference was found between LAVH and vaginal hysterectomy regarding postoperative pain.

As far as the complications are concerned in NDVH vault hematoma was seen in two cases $(5.6 \%)$, infection in one $(2.8 \%)$, bladder injury in one $(2.8 \%)$ and fever in two $(5.6 \%)$ cases. In LAVH, vault hematoma was seen in one case $(3.2 \%)$ infection in two $(6.4 \%)$ cases, gut injury in one $(3.2 \%)$, and fever in one $(3.2 \%)$ case.

\section{CONCLUSION}

Both LAVH and NDVH were initiated with the contemplation to avoid scar in the abdomen and at the same time making utmost utilization of the natural orifice. LAVH has the advantage of visualization of the pelvic structure from above and occasional dissection and adhesiolysis. The proportion of the operation which should be done laparoscopically will vary and should depend on the amount of the operation which can most conveniently, quickly and safely be done from above. But NDVH supersedes in its approach through the naturally created route, being faster, less expensive and results in a similar hospital stay and convalescence. At the same time it avoids the misery and disfiguration of a scar celebrating the cosmetic outlook. At what stage the transition from one approach to the other takes place will depend on the nature of the pathology, size of the uterus, equipments available and skill and preference of the operator.

\section{REFERENCES}

1. Khanam NN, et al. Non descended vaginal hysterectomy is a reasonable alternative to LAVH? South Asian Fed Obstet and Gynaecol 2009 Jan-Apr;1(1):47-52.

2. Bobin L, Maciolek-Blewniewska G, Malinowski A, et al. Operating time of laparoscopically assisted vaginal hysterectomy (LAVH): the causative factors and the course of the postoperative period. Ginekol Pol 2007 Mar;788(3):204-209.

3. Johnson N, et al. Surgical approach to hysterectomy for benign gynaecological disease. Cochrane Database Syst Rev 2006 Apr 19;(2):CD003677.

4. Drahonovsky J, et al. A prospective randomized comparison of vaginal hysterectomy, laparoscopically assisted vaginal hysterectomy, and total laparoscopic hysterectomy in women with benign uterine disease. Eur J Obstet Gynecol Reprod Biol 2010 Feb;148(2):172-176. Epub 2009 Nov 18.

5. Song T, et al. A review of the technique and complications from 2,012 cases of laparoscopically assisted vaginal hysterectomy at a single institution. Aust NZJ Obstet Gynaecol 2011 Jun;51(3): 239-243.

6. Roy KK, et al. A prospective randomised study of total laparoscopic hysterectomy, laparoscopically assisted vaginal hysterectomy and non-descent vaginal hysterectomy for the treatment of benign diseases of the uterus. Arch Gynecol Obstet. 2011 Oct;284(4):907-912. Epub 2010 Dec 8.

7. Drahonovsky J, et al. A prospective randomized comparison of vaginal hysterectomy, laparoscopically assisted vaginal hysterectomy, and total laparoscopic hysterectomy in women with benign uterine disease. Eur J Obstet Gynecol Reprod Biol 2010 Feb;148(2):172-176. Epub 2009 Nov 18.

8. Horng SG, et al. Bladder injury after LAVH: a prospective, randomized comparison of vaginal and laparoscopic approaches to colpotomy during LAVH. J Am Assoc Gynecol Laparosc 2004 Feb;11(1):42-46.

9. Chang WC, Huang SC, Sheu BC, Chen CL, Torng PL, Hsu WC, et al. Transvaginal hysterectomy or laparoscopically assisted vaginal hysterectomy for nonprolapsed uteri. Obstet Gynecol 2005; 106:321-326.

10. Candiani M, Izzo S, Bulfoni A, Riparini J, Ronzoni S, Marconi A, et al. Laparoscopic vs vaginal hysterectomy for benign pathology. Am J Obstet Gynecol 2009 April;200(4):368.

11. Bronitsky C, et al. A comparison of laparoscopically assisted vaginal hysterectomy vs traditional total abdominal and vaginal hysterectomies. J Gynecol Surg 1993;9(4):219-225. 